\title{
Public service delivery in Uganda: reconsideration of grand corruption
}

\section{David Mwesigwa}

Lira University, mid-north of Uganda davidmwesigwa22@gmail.com

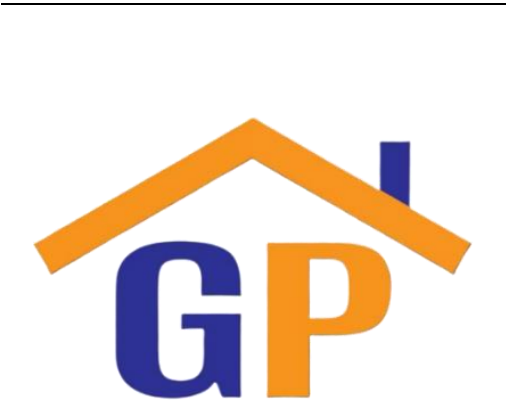

Article History

Received on 15 January 2021

Revised on 27 January 2021

Accepted on 28 January 2021

\begin{abstract}
Purpose: This review intends to ascertain and analyse available literature for the degree of corruption in the Ugandan public organisations and how they can be enhanced to get rid of corruption.
\end{abstract}

Research methodology: Focussed Mapping Review and Synthesis approach were adopted to unpack corruption in public organisations. We examine obtainable literature using thematic approach.

Results: The review exposes potential influence of both predisposing factors and precipitating factors in terms of socioeconomic and political dimensions. Nonetheless, Public organisations in Uganda can be enhanced to get rid of corruption by enforcing a robust blend of all the three clusters of instruments of accountability; internal, legal and external.

Limitations: Since the study was largely based on Uganda, its outcomes may not be generalized.

Contribution: This explanatory review underscores the apathy of government machinery to rid public organisations of corruption. There is a need for politicians and policy experts to conduct additional analysis of corruption within the public sector.

Keywords: Corruption, Predisposing factors, Precipitating factors, Accountability

How to cite: Mwesigwa, D. (2021). Public service delivery in Uganda: a reconsideration of grand corruption. Dynamics of Politics and Democracy, 1(1), 1-13.

\section{Introduction}

The degree to which corruption is able to suppress a public organisation in the fourth industrial revolution is appealing to a number of researchers and decision-makers worldwide. This attention is twofold, namely: the first issue is that there are pointers that bureaucracy has become very dynamic as competition and innovative organisational structures develop, and with cutting-edge science and technology revolutionising the entire public sector (Moussa, McMurray \& Muenjohn, 2018). The consequence of innovation is that it is no longer adequate for a public organisation to continue providing the service to the citizens in the same conventional style (adhering to the same hierarchy, specialisation, division of labour and operating procedures) but it should make available such services in the most cost effective way that neither puts an extra burden to the taxpayer nor compromises the ultimate quality of the service itself (Whelan, 2015:538). The second issue is that present public organisations are not delivering services with the kind of proficiency and ethical value desired so as to be able to survive competition and varying work of better alternatives provided by the private sector (Moulick \& Taylor, 2017:994). For example, financial slack is common in a number of government agencies and local governments in Uganda.

Public organisations have seen numerous criticisms for the view that their bureaucracy has not succeeded in evolving so as to meet the socio-economic needs of citizens in a number of sub-Saharan African (SSA) countries (Willis, 2018:298); this has dented the quality of service delivered to citizens albeit higher price (Chen, Dahlgaard-Park \& Yu, 2014:1200). While the world committed itself to the 
2030 agenda for sustainable development in which the third agenda aims "to ensure that all human beings can enjoy prosperous lives..." (Cerilli, 2016), suggestions from previous studies reveal that there is a high degree of corruption affecting a number of public organisations in Uganda (such as Muhumuza, 2016). Evidence gives emphasis to the view that corruption in Uganda is not only a consequence of socio-economic dynamics but because of failure, by the political leadership, to sanction comparable punishment to the perpetrators (Flanary \& Watt, 1999; Faller, 2015). As a consequence, elite corruption has been used to facilitate the government of Uganda to strengthen the allegiance of elected leaders besides mobilising support for sustaining the system in control. A study by Tangri and Mwenda (2008:179) reveals that since corruption has been used to reinforce political support for the regime, state leaders cannot afford to fight it. An Anti-Corruption Coalition report reveals that a wide range of sectors and government institutions including health, education, and police have not been spared.

The government of Uganda has acknowledged that corruption is one of the main challenges facing the country. For example, the Inspector general of police reveals that corruption is the biggest challenge facing the institution (Kato, 2019). One of the most worrying concerns is that a number of cases reported to relevant government bodies, such as the Inspectorate of government and the Criminal investigations department, are neither given the preferred consideration nor put on trial. For a decade, the trial policies have exposed what is perceived as internal weaknesses within the anti-corruption bodies thus casting a shadow of doubt about the resolve behind various anti-corruption schemes in Uganda (Quarcoo, 2009:33). As a result, corruption remains one of the key impediments to the country's poverty reduction frameworks such as National agricultural advisory services, prosperity for all, operation wealth creation, youth livelihood programme and women entrepreneurship programme. A number of corrupt officials that have not been prosecuted by Courts of law are those that hide behind the guise of deep-seated support to the ruling political party and attract immense favour from the chief executive. As a consequence, the voting population ends up voting back into office the very corrupt candidates seeing that a single honest individual cannot reduce corruption which is systemic (Faller, 2015:450). Similarly, studies reveal that there is general tolerance within number of public organisations otherwise entrusted with the mandate to ensure public financial accountability such as the Inspectorate of government, in part, due to dearth of commitment by the political leadership and facilitation to the anti-corruption institutions (Muhumuza, 2016:79). The results of this study are supportive of other similar studies, such as Herath, Lindberg and Orjuela (2019) which revealed that while the scale of corruption is not uniform, it is common, inescapable and entrenched in the public life in a number of communities. Consequently, the degree of corruption exposed in these studies upholds the view that a number of public organisations in Uganda are not devoted to fighting corruption. With the discovery of oil and gas and with the prospect of considerable dividends from oil revenue coming on board in the near future, Uganda is destined to face major challenges with regard to the problem of corruption.

The problem of corruption is a pronounced challenge to public service delivery, and poses questions regarding the significance of public organisations in the world (Asongu, 2013:36). While citizens expect to get decent and quality services, the degree of leakage through numerous forms of corruption such as bribery, embezzlement, false accounting, fraud, influence peddling, and nepotism continue to compromise the administrative processes (Krylova, 2018:132). In Uganda, just like in a number of parts of Africa, such leakage has had a direct link with dominant ethnic clusters (Isaksson, 2015). This ambivalence is clear from the perspective of good governance, which emphasises effective public organisations as a precondition to guaranteeing that resources reach the proposed beneficiaries. Nevertheless, with present-day corruption contributing to poor service delivery, the vision of attaining good governance becomes a deception for a number of citizens (Molina et al 2017:490). Therefore, in light of the incidence of corruption in Uganda, this article offers alternatives for policy consideration by governments, multilateral organisations and corporate bodies undertaking business with the government of Uganda as a means to reducing corruption in public organisations.

Whereas a number of options have been offered by academics (such as Umam et al., 2018) seeking means by which corruption in the public organisations can be frustrated, not any of these options 
appear suitable for the condition in Uganda where the cravings of wealth accumulation are not linear. Obtainable studies (such as Muhumuza, 2016), on corruption are scarce, and they consider the CPIs in Uganda vis-à-vis other nations in the region or worldwide. But, they do not bring to the fore other mechanisms of dehorning corruption and ways in which such measures can be enhanced among public organisations.

\section{Literature review and hypothesis development}

\subsection{Corruption - by way of definition}

Rose (2018) notes that while a number of scholars and organisations have put forth several definitions, none has offered an assertive connotation of the term. The Anti-corruption Act of Uganda, describes corruption as soliciting and acceptance of anything by a public official, diversion of public funds as well as fraudulent acquisition and concealment of property (Government of Uganda, 2009). It refers to the "abuse of public interest and the undermining of public confidence in the honesty of procedures, structures and establishments that support the interest of public" (The Tax Justice Network, n.d). In addition, corruption comprises the misuse of delegated authority for private advantage (Transparency International, n.d). Corruption is practiced at every level of public organisations in a number of African societies including Uganda. A study by Tvedten and Picardo (2019) reveals that modest corruption has direct consequences for the poor be they urban or rural and has been fused in the everyday life of communities. Although a good number of the underprivileged associate with the vice through quiet receipt and submission, its effects are felt among the underprivileged, who cannot manage to cooperate in corrupt dealings and are left out from essential public affairs and public services.

Corruption in public organisations of Uganda occurs both at central government level and at local government level. A study by Nystrand (2014:827) reveals that central government corruption is linked to disbursement of funds meant for different programmes and projects while local government corruption occurs through a number of transactions made between the local business community and local leaders. The local level corruption is perceived, by citizens, to be normal and acceptable since it is used to facilitate transactions between the public and the local government. A separate study by Gauthier and Goyette (2014:2763) found that there is a negative relationship between kickback and tax overheads involving firms and tax collectors. This suggests that the higher the kickback and the tax payment registered by the government of Uganda. That is probably why Tangri and Mwenda (2010:42) link corruption to the politics of presidential tenure in the case of Uganda.

\subsection{Economic effect of corruption}

Obtainable studies a number of economic effects resulting from corruption, namely: High transport costs due to increased cost of fuel thus the gap between the rich and the poor (gross inequality) increases. For example, a study by Brent (2017) reveals how costs on transport affect the socioeconomic lives of Ugandans. While there is the economic has been applauded for its fast growth over the past decade, there is also a factor of skewed wealth where a very small group of individual own much of the wealth. This is followed by increased number of street children in every town, increased number of commercial sex workers in every trading centre, increased number of mafias and increased cases of child kidnap and murder for ransom (Muldoon et al 2017). In addition, due to rampant corruption, there is lack of tangible benefits from rural development projects such as Youth Livelihood Program (YLP), Youth Entrepreneurship Scheme (YES) and Operation Wealth Creation (OWC), high cost of living and hence a low standard of living, high cost of energy and telephone network, too large external debt and internal debt, and high interest rates (Nystrand, 2014). These are accompanied by environmental degradation due to loss in non-renewable resources, high government expenditure, high taxation both direct and indirect, unstable macroeconomic climate, limited specialisation and exchange, and shortage of savings to finance development (Kahangirwe, 2011).

\subsection{The intersection between theory and practice}

Different perspectives have been put forth regarding the idea of corruption. The economic perspective looks at the effect of rational selfishness, efficacy as well as official regulative structures in describing the growth of corruption (Pillay, 2014). However, this perspective offers limited results in combatting 
corruption as it fails to embrace the regulative and rational structures. As a consequence, effective war against corruption ought to embrace the intricate dealings among formal reason, the essential resources for sustaining the removal of corruption, and the formal businesspersons who try to abolish corruption. Scholars (such as Ardelyanova and Obryvalina, 2018) have found that level of corruption has a direct relationship with inequality indicating that the high the level of corruption the high the level of inequality.

In this article, interest is directed towards grand corruption. Lasslett (2017:30) applies three elements to demonstrate grand corruption, namely: it encompasses substantial monetary value, in either financial form or asset form; the act of corruption is not a remote element, instead it is a subsection of a structure within the wider organisational administration; it is executed by superior members that have the potential to influence the policy direction in public organisations.

\subsection{Corruption as a means to a preferred end and as an end in itself}

A study by Scanlan (2004:316) reveals that corruption is closely related with bribery and no corruption can take place without the element of bribery. On the one hand, corruption is used as a preferred end particularly when seen from the side of the bribe giver in a number of ways: to gain a job or a contract; to gain an election victory; to triumph a court case; to win government education scholarship, to gain from tax reduction or tax waver or tax holiday, to mention just a few. On the other hand, corruption is used as an end in itself when seen from the side of the bribe taker seeing that the individual or group gains economically from the resources presented to them. In other cases, the bribe taker can demand for and be offered sexual favour in exchange for any of the above opportunities especially when the bribe giver is a female (in the case of Uganda). The benefits accruing from corruption from both sides, the giver and the taker are either short-term or long-term. The short-term gains include triumphant in a court case or sexual contact while the long-term gains include election victory; acquisition of advanced knowledge and skills through education and training gained from government scholarships, economic progress as a result of tax reduction or tax waver or tax holiday.

\subsection{Corruption in public organisations}

Public organisations are prone to corruption due to a range of behavioural factors. For example, a study by Borlea, Achim and Rus (2019) reveals that power distance; trust in legal system, happiness and religion are the most important behavioural determinants of corruption, explaining about $50 \%$ of all acts of corruption around the world. The study suggests that a higher power distance, a lower level of trust in legal system, a lower level of happiness (measured by subjective well-being) and a higher level of religiosity conduct to a higher level of corruption. For a number of less-developing countries such as Uganda, corruption has become a necessity in every government transaction. This implies that it is no longer news to report about any corrupt official instead it makes a lot of news when one is not corrupt as a number of observers wonder such a person can survive devoid of it. In fact, there is a popular question in Uganda nowadays; the amount embezzled is what makes headings but not the action itself.

\section{The problem}

The main focus of this review is to discuss the existence of official corruption in selected public organisations in Uganda. Transparency International (n.d) reveals that Uganda has retained its rank at 151 out of 180 (thus recording 26 percent) in terms of global standings on Corruption Perception Index (CPI). In the East African region, Rwanda is the ranked top and worldwide it is ranked $48^{\text {th }}$, Tanzania is ranked second best at number $103^{\text {rd }}$ worldwide, Kenya is ranked third best at $143^{\text {rd }}$ worldwide. Uganda is forth best at 151 while Burundi is fifth and it is placed at 157 worldwide as South Sudan and Somalia are sixth and seventh being placed 179 and 180 correspondingly. There are indications that public organisations in the region and Uganda in particular are unable to attain normalcy in terms of delivering on their mandate due, in part, to widespread corruption (Tangri \& Mwenda; Draku \& Agencies, 2018; Kato, 2019). This condition is a huge challenge for the significance of public organisations thus necessitating immediate consideration. As a result, this review examines aspects among public organisations in Uganda as potential means by which selected public organisations can be facilitated to get rid of corruption 


\section{Objective of the study}

The main objective of this review is to examine the degree of corruption among selected public organisations in Uganda. In attaining this objective, four questions are answered, namely: (a) what are the predisposing factors to corruption in public organisations in Uganda? (b) What are the precipitating factors to corruption in public organisations in Uganda? (c) In what ways can public organisations be facilitated to get rid of corruption?

\section{Research methodology}

This review adopted a Focussed Mapping Review and Synthesis (FMRS) approach to unpack corruption in public organisations in Uganda as well as worldwide. According to Bradbury-Jones et al (2019), FMRS has four features that are worth for this review, namely: (a) it looks at the distinct field of information instead of a body of proof; (b) it builds an expressive structure of vital features of research in the field instead of synthesising the results; (c) it clarifies on the overall approach to producing evidence rather than the condition of the evidence; and (d) it applies a wider epistemological setting. Consequently, every information gathered was cross-referenced and organised along the emerging themes. This method was found to be very effective when dealing with topics that are very sensitive and or emotional; information desk analysis allows the investigator to collect information with ease.

\section{Results and discussions}

\subsection{Predisposing factors to corruption among public organisations in Uganda}

This involves factors that influence individuals in public organisations towards any form of corruption. A number of factors predisposing corruption have been identified in obtainable literature and discussed under three groups, viz.: social, economic and political.

a) Social factors - attention focuses on organisational culture, unreliable administrative monitoring, ineffective management of community expectations and community pressures, deficiency in administrative counselling, and organisational transformation.

\section{The organisational culture}

A number of public organisations in Uganda have been criticised for not only lacking in ethics but also for being too soft, lenient and forgiving to the corrupt and as a consequence liable to persuading public servants and or officials into acts of honesty. For example, a study by Mbau and Gilson (2018) reveals that there is prospective effect of proportions of organisational culture such as power distance, evading uncertainty, and group and official collectivism over the execution of programmes in public organisations. While Mbau and Gilson show that such effect is facilitated through practices within the organisation such as commitment and involvement in decision-making as well as styles of management, they can as well be undermined by corruption within the organisation.

\section{Unreliable administrative monitoring}

Public organisations in Uganda are dogged by erratic administrative monitoring, grossly deficient monitoring mechanisms and monitoring tools, less-participatory monitoring processes as well as nonoperational monitoring procedures. In addition, political oversight is marred by political favour and dishonesty (Molina et al., 2017); the combination of these issues has a direct influence to tendencies of corruption in a number of ways such as fraud, deceit and falsification of key administrative documents.

\section{Ineffective management of community expectations and community pressures}

Ugandan public organisations lack adequate skill on the effective tools to managing community expectations and community pressures in dynamic conditions. A practical study by Yekini, Adelopo and Adegbite (2017:445) demonstrates that public officials regard community expectations and community pressure as the greatest influence towards corruption while a number of them considered their communities to benefit from the their positions even if it meant using dishonest means to achieve that. This, furthermore points to a deficiency of the patriotic spirit in public organisations all of which favouring the practice of corruption.

\section{Deficiency in administrative counselling}

Available literature reveals that administrative counselling is rarely rendered in the Uganda public organisations. For example, a study by Mitchell, Oakley and Dunkle (2019:100) reveals that every 
public organisation needs to embrace organisational counselling services. Moreover, in organisations where such services are rendered, they do not provide professional services since the individuals entrusted with the units are either not qualified or lack essential exposure on how to handle key issues such as peer pressure. As a consequence, public officials become victims of peer pressure which may translate into acts of corruption.

\section{Organisational transformation}

A number of public organisations are becoming more economical and less clogged as more employees are forced to leave due to more effective means of doing work coupled with advanced science and technology. A number of civil servants in public organisations do not seem to appreciate this irreversible trend and as a consequence are willing to do whatever it takes to enter and retain the job so as to have better opportunities to achieve economic success in an era of high unemployment. A study by Hardy et al (2018:89) established that it is too hard to tell who will get or retain a particular job since organisations have different preferences such as level of education and skill relevance; an issue which attracts fraud as each job holder tries to find means of standing out of the crowd.

b) Economic factors - they include: Existence of poverty among the Ugandan elite, demand for post-University job experience, and horizontal competition among public officials.

\section{Existence of poverty among the Ugandan elite}

There is growing poverty among the educated class in Uganda especially by the time one graduates from University. According to Hassan and Birungi (2011) a number of poor households have to endure with scarcity when seeking social capital; this issue is made worse when such parents are educating their children at University which is not affordable to many in the countryside. However, nothing is painful in Uganda than graduating and stay on the streets for an indefinite number of years. A study by Ho Mok (2018:592), which was conducted in China, found that while the number of graduates from both Universities and other tertiary institutions has increased, many of them cannot find jobs within two years after graduation; this trend has been caused by failures over how the policy is coordinated, understood and applied. This has ostensibly led these graduates to become dishonesty, which leads to corruption being practiced by those searching for the few job openings and job promotion spaces in the few public organisations.

\section{Demand for post-University job experience}

In Uganda, there is provision for graduates from University to have certain work experience in a relevant organisation. While a number of direct entry University students can only gain some form of work experience during Student industrial training, a number of public organisations will not consider such as relevant. Regarding the ploy by public organisations to reject fresh graduates, accessible studies shows that this challenge is not only limited to Uganda but other nations in Africa. For example, a study by Pitan (2016:4) reveals that there is inadequate collaboration between universities and employers of graduates.

\section{Horizontal competition among public officials}

A number of officials in public organisations in Uganda have an undeclared competition between individuals at the same rank in different organisations. For example, a principal accountant in the Uganda National Roads Authority (UNRA) is likely to be seen competing with a counterpart in Kampala Capital City Authority (KCCA). This sort of competition manifests in the amount of wealth each of the two accumulate in a particular period of time, say five years. It is unfortunate that the two will engage in acts of dishonesty as a means to amass as much wealth in a short time as possible (Tangri \& Mwenda, 2008).

c) Political factors - focus is directed to four elements, namely: tolerance in government policy, tolerance in the legal structure, state patronage, and the political culture.

\section{Tolerance in government policy}

When there is an extensive engagement of citizenry which is directed towards enhancing accountability as well as addressing key anomalies at every point of decision making in a public organisation, transparency and accountability of management is realised. In their study, Mondlane, Claudia and Khan (2016) reveal that low corruption is associated with a strong process of citizen engagement in public governance and public accountability. This suggests that while corruption can emerge from inside the authority of public organisations, tolerance in government policy is key is 
maintaining the vice. Uganda has been criticised by a number of commentators for its tolerance to acts of corruption especially when those perpetrators are politically connected to the regime (see Muhumuza, 2016; Tangri \& Mwenda, 2008). This impunity predisposes a number of public officials to acts of corruption.

\section{Tolerance in the legal structure}

In a number of Ugandan public organisations, corruption is so entrenched that officials cannot survive without it. While a few civil society organisations have tried to push for criminal proceedings against corrupt officials, a study by Lasslett (2017:30) reveals that the corrupt have authority to influence not only the policy framework but criminal proceedings too. As a consequence, the corrupt are likely to frustrate every criminal procedure brought up against them (Mutonyi, 2002). This ploy of hiding behind several socio-political complications has influenced a good number of officials to carry on with acts of corruption with impunity.

\section{State patronage}

Empirical studies have shown that the presence of state patronage has become fashionable in Ugandan public organisations. For example, it was found that a number of public organisations ride on a system of patronage rather than serving the interests of the general public and where patriotism exists, official programs are underfunded. In public organisations where professionalism exists, their programmes and projects are continually choked on the pretext that they are "not cooperative". Such organisations are labelled as "dry" institutions. It is revealed that citizens rarely enjoy the quality of services that is anticipated.

\section{The political culture}

The reality of the current political culture is that it is be becoming more politically correct for a public official to engage in corrupt tendencies. Public officials, especially nominated by the executive, face a challenge of balancing political interests of the appointing authority and non-partisan professionalism because they are directly conscripted into the semi-political arena of the state. They include Permanent secretaries, executive directors and managing directors. For example, this study found that it is often hard for a political appointee to tore between the lines. As a consequence, such officials end up being enrolled into the very culture which is based of scoring political goals rather than meeting the pressing needs of communities.

\subsection{Precipitating factors to corruption among public organisations in Uganda}

These are aspects or issues that cause or give rise to corruption in public organisations; they have been classified in terms of the environment of public organisations and internal structures and processes.

a) The environment of public organisations - in Uganda, the environment is characterized by diversity and intensity of demands, Multiplicity, complexity and debatable nature of goals, Public scrutiny and accountability among public officials, and Requirements in the public organisations.

\section{Degree of diversity and intensity of demands}

There is greater diversity and intensity of demands and pressures of decision making in public organisations. For example, a study by Demir et al (2018) reveals that a manager in a public organisation is likely to receive letters from friends seeking to employ their relatives. And since the state machinery entrusted with fighting corruption has almost collapsed, the job recruitment process has given rise to corruption due to the emergence of 'lobbying' for every job opportunity available. A separate study by Sindik (2015:130) shows that in a number of cases, lobbying allows the public organisation to circumvent the very specifications otherwise required for a particular job as a result of demands and pressures presented by decision makers there in.

\section{Multiplicity, complexity and debatable nature of goals}

There are multiple, complex and debatable goals in a number of public organisations in Uganda such as National Water and Sewerage Corporation (NWSC) which is entrusted with supply of clean and safe water to every citizen in the country. According Mugisha and Borisova (2010), NWSC can restrain one from accessing a service if one failed to pay, yet water is an essential need for humanity. Incidentally, NWSC supply water to other public organisations in the country such as Hospitals and Universities which do not clear their bills in time. Since hospitals are perceived to be lifesaving organisations, political leaders demand that NWSC must not fail to supply water to any hospital like Mulago National Referral Hospital. Yet, Mulago operates an annual budget that includes water; this 
has given rise to corruption as individuals otherwise entrusted are given amnesty under the guise of essential human needs.

\section{Public scrutiny and accountability among public officials}

There is greater insistence on public scrutiny and accountability of public officials in public organisations. While scrutiny and culpability are essential in ensuring that public organisations become efficient, a study Muhumuza (2016) reveals that Uganda's political class as well as the civil society are blunt swords which only talk for political capital or as a way of giving accountability to the donors that they are working. In their study, Tumwebaze et al (2018) indicate that a number of Audit Reports are scantly debated and recommendations are never implemented since individuals otherwise implicated are perceived to be big-fish in the political establishment, an issue which triggers elite corruption.

\section{Requirements in the public organisations}

There is a requirement in Ugandan public organisations to make the 'right' decision and there is also a need to mobilise political support for the outcomes. For example, as a public organisation, every decision must be technically sound and politically acceptable. This leads to corruption from both angles; right decisions and political support. A number of managers in public organisations lack adequate qualifications for the job, but political expedience, they are offered such jobs. According Mwelu et al (2019), such managers are deficient in skill, regulatory structures and in obedience with the structures due to technical deficiencies. Political support in Uganda has turned to the ruling party caucus which should generate a consensus that allows the party to score political goals rather than meet the needs of communities.

Other environmental aspects to public organisations identified from obtainable literature are:

- Uncontrolled hunger, among public officials, to accumulate short-term wealth triggers acts of corruption in Uganda;

- the Ugandan public, save for a few members of the civil society, give the impression of appreciating the corrupt especially political leaders who keep winning elections;

- Reluctance, by government, to make corruption a very risky practice because if it was the case then few public officials would engage in the vice;

- Lack of deterrent laws and failure to award harsh punishment the corrupt; for example, a Report by the Anti-corruption coalition of Uganda (Muhumuza, 2016) reveals that those that siphon huge monies are either given amnesty or awarded inconsequential punishment.

\section{b) Internal structures and processes}

In Ugandan public organisations, there are greater requirements given the scale of bureaucracy, the range of governmental activities, and diffusion of authority, time horizons, and source of revenue.

\section{Scale of bureaucracy}

The scale of bureaucracy is so interlaced that it is a commonplace to find two or more organisations undertaking similar functions. For example, Uganda Registration Services Bureau (URSB) and National identification and Registration Agency (NIRA) or Uganda Electricity Distribution Company Limited (UEDCL) and Uganda Rural Electrification Agency (UREA) or Uganda National Roads Authority (UNRA) and National Road Fund (NRF). For example Golooba-Mutebi and Hickey (2016) describe it as "institutional multiplicity" that gives rise to elite corruption manifesting through regime endurance tactics.

\section{The range of governmental activities}

The activities range between government ministries and government agencies as well as local governments and Directorates at State House. While this range is aimed to enhance accountability through counter investigations, a study by Atwortwi and Helmsing (2014:308) indicates that it has instead increased political patronage and a variant of gerrymandering which have amplified the ultimate cost of administration as well as spreading out avenues for elite corruption.

\section{Diffusion of authority}

Authority in public organisations is so diffused and or dispersed that every level of government, from office of the President to the village, everyone has some measure of power to control. While this centralised and decentralised system is helpful in facilitating specific issues to be handled at 
respective points, it has instead been seized by the Anti-Corruption Unit of State House which often bypasses every other power centre under the guise of absolute power gained from the appointing authority. According to Katureebe (2019), the Anti-Corruption Unit at State House has been credited for being hands-on however; it has failed to coordinate with other Anti-Corruption Agencies of the state such as the Inspectorate of Government, an issue which complicates the functioning of public organisations and triggering rather than taming corruption.

\section{Time horizon}

Regarding time horizon, a public manager tends to have relatively short time horizon dictated by political necessities and the political calendar. This is issue is further heightened by the new public management approach which requires public managers to serve on contract terms on the doctrine of public choice and managerialism. Kalimullah, Alam and Nour (2012:2) reveal that the above view emerges from the ideals of administration which give importance to effectiveness, trustworthiness and objectivity, as well as strength and flexibility of systems. Since early 2000, there has been emphasis for public organisations in Uganda to shift towards private sector management styles. A number of public organisations such as UNRA have achieved this shift however, the same shift brings with it loopholes of corruption in a number of ways. While the issue of recruiting managers to serve on contracts only renewed once might be a positive gesture, it has been dented with influence peddling and outright fraud. Nonetheless, a study by Mwelu (2019) reveals that employment of a competent team is vital in subduing influence-peddling. According to Sabiiti (2019), the recruitment process in a number of public organisations is still dotted with corruption.

\section{Source of revenue}

Public organisations obtain their revenue from the budget; this is a very political process since the individuals that are entrusted to apportion funds are partisan. While it is true that the politicians do not draw the budget framework paper on their own; it is done by the bureaucrats in various public organisations. For example, in a number of countries, including Uganda, bureaucrats control the process of national budgeting due to several factors such as proficiency, cover-up, handling of statistics, and dearth of transparency (Cohen, 2013). In Ugandan public organisations, bureaucrats have become yet more proficient in committing fraud during the handling of budget statistics as well as executing the different government programmes and or projects.

\subsection{Enhancing public organisations to get rid of corruption}

Public organisations in Uganda can be enhanced to get rid of corruption enhancing the available instruments of accountability in the country, namely: Internal instruments, Legal instruments and External instruments.

a) The internal instruments can be used to ensure accountability within the internal operation of the organisation. These are several including:

- Executive meetings - which take place at departmental level with the aim to ensure that programmes and projects are implemented in accordance with the set guidelines and budget line.

- Internal commissions of inquiry - these can be used when a serious problem, such as incidences of corruption, has been detected within the organisation with the view to clean up organisation before conditions get out of hand.

- Internal audit - this department can help to follow up public funds from the time it is released to the last point where they spend it; this will check on every program and make sure that only the monies required are released (Tumwebaze et al 2018).

- Fiscal powers - these are powers conferred by law to specific individuals within the public organisation to ensure accountability such as Permanent secretaries.

b) The Legal instruments can be used to ensure accountability by exploring legal redress when the internal mechanisms have failed. They include:

- The Parliament of Uganda has several sources of power to reinforce accountability; they include: budgetary allocation to various ministries; it holds the mandate of voters; and, freedom to debate any motion including honesty in public organisations. A study by Doro 
and Kufakurinani (2018:50) reveals that the Parliament of Uganda has failed to play a critical role of enforcing accountability.

- Parliamentary committees - these focus specific issues such as budgeting. Committees such as Public Accounts Committee (PAC) and the Committee on State Assurances and Statutory Enterprises (COSASE) can apply their powers to deny funding to any public organisation as long as they feel they are not satisfied with how public expenditure is handled.

- The Police criminal investigations department has powers to investigate any public official suspected of failing to follow the regulations through diversion of public resources.

- The Inspectorate of government stands in a strategic position since it is neither in nor out of government; the office can investigate and or cause prosecution of any public official suspected to have committed any acts of corruption.

- The courts of law, especially the Anti-corruption court, can be used to ensure that the public is given a fair hearing as well as giving deterrent punishment in cases where a public official if found to have betrayed government through acts of fraud (Muhumuza, $\underline{2016}$.

c) External instruments are very helpful in ensuring accountability by helping to expose acts of suspected corruption; they include:

- The Auditor General - this office has powers to scrutinise the performance of every government Ministry or public organisation including powers to prosecute any official who fails to account for their actions and the office may deny funding to any department of organisation due to misappropriation.

- Civil Society Organisations especially the Media plays a key role of exposing dubious actions that public officials may engage as well as causing public awareness regarding fraudulent acts. According to Grebe (2016:503), the efficacy of civil society has not been allowed by a rigid administrative philosophy and establishments that discourage verbal censure.

- The Ministry of ethics and integrity - although it is often underfunded, the Ministry has the powers it can apply to expose and or cause to prosecute any public official suspected of indiscipline including fiscal dishonesty.

\section{Conclusion}

In this section, the outcomes have been presented and discussed concurrently given that I took a desk review. Consequently, the outcomes are presented along three themes, namely; predisposing factors to corruption, precipitating factors to corruption, and strategies to enhance government public organisations to get rid of corruption.

\section{Limitation and study forward}

This explanatory review underscores the apathy of government machinery to rid public organisations of corruption. Consequently, there is a need for politicians and policy experts to conduct additional analysis of corruption within the public sector.

\section{References}

Ardelyanova, Y., and Obryvalina, O. (2018). Comparative analysis of inequality, Corruption, and Trust studies in modern societies. Mediterranean Journal of Social Sciences, 9(1), 65-9.

Asongu, S.A. (2013). Fighting corruption in Africa: do existing corruption-control levels matter? International Journal of Development Issues, 12(1), 36-52.

Awortwi, N., and Helmsing, A.H.J. (2014). Behind the façade of bringing services closer to people: The proclaimed and hidden intentions of the government of Uganda to create many new local government districts. Canadian Journal of African Studies, 48(2), 297-314. 
Borlea, S., Achim, M., and Rus, A. (2019). Behavioural determinants of corruption: a cross-country survey. Studia Universitatis, Vasile Goldis. Arad-Economics Series, 29(1), 21-39.

Bradbury-Jones, C., Breckenridge, J.P., Clark, M.T., Herber, O.R., Jones, C., and Taylor, J. (2019). Advancing the science of literature reviewing in social research: the focussed mapping review and synthesis. International Journal of Social Research Methodology. Accessed: DOI:10.1080/13645579.2019.1576328.

Brent, R.J. (2017). Using the travel cost method to value visits and stigma in connection with ARV adherence in Uganda. Applied Economics, 49(5), 477-497.

Cerilli, S. (2016). The 2030 agenda for sustainable development: Goals, targets and indicators. Food and Agriculture Organisation/World Bank Group. Kampala.

Chen, Z. Dahlgaard-Park, S.M. \& Yu, L. (2014). Service quality management and ecosystem theory. Total Quality Management \& Business Excellence, 25(9-10), 1190-205.

Cohen, N. (2013). The power of expertise? Politician-bureaucrat interactions, national budget transparency and the Israel healthcare policy. Policy Studies, 34(5\&6), 638-54.

Demir, T., Reddick, C.G., Ponornariov, B., and Flink, C.M. (2018). Does power corrupt? An empirical study of power, accountability, and performance triangle in public administration. International Journal of Public Administration. Accessed: DOI:1080/01900692.2018.1506934.

Doro, E., and Kufakurinani, U. (2018). Resource curse of governance deficit? The role of Parliament in Uganda's oil and Zimbabwe's diamonds. Journal of southern African studies, 44(1), 43-57.

Draku, F \& Agencies. (2018). Uganda maintains positions in latest global corruption index. Daily Monitor Uganda. Thursday February 22.

Faller, J.K. (2015). The system matters: Corruption and vote choice in Uganda. Commonwealth \& Comparative Politics, 53(4), 428-56.

Flanary, R. \& Watt, D. (1999). The state of corruption: A case study of Uganda. Third World Quarterly, 20(3), 515-36.

Gauthier, B. \& Goyette, J. (2014). Taxation and corruption: theory and firm-level evidence from Uganda. Applied Economics, 46(23), 2755-2765.

Golooba-Mutebi, F., and Hickey, S. (2016). The master of institutional multiplicity? The shifting politics of regime survival, state-building and democratisation in Museveni's Uganda. Journal of Eastern African studies, 10(4), 601-618.

Hardy, W., Kielczewska, A., Lewandowski, P., and Magda, I. (2018). Job retention among older workers in central and eastern Europe. Baltic journal of economics, 18(2). 69-94.

Hassan, R., and Birungi, P. (2011). Social capital and poverty in Uganda. Development Southern Africa, 28(1), 19-37.

Herath, D. Lindberg, J. \& Orjuela, C. (2019). Swimming upstream: fighting systemic corruption in Sri Lanka. Contemporary South Asia. Accessed: DOI:10.1080/09584935.2019.1579171.

Ho Mok, K. (2018). Promoting national identity through higher education and graduate employment: reality in the responses and implementation of government policy in China. Journal of Higher Education Policy and Management, 40(6), 583-597.

Isaksson, A. (2015). Corruption along ethnic lines: A study of individual corruption experiences in 17 African countries. The Journal of Development Studies, 51(1), 80-92.

Kahangirwe, P. (2011). Evaluation of Environmental Impact Assessment (EIA) practice in western Uganda. Impact assessment and project appraisal, 29(1), 79-83.

Kalimullah, N.A., Alam, K.M.A., and Nour, M.M.A. (2012). New Public Management: Emergence and Principles. BUP Journal, 1, 1-22.

Kato, J. (2019). Corruption our top problem - IGP Ochola. Anti-Corruption coalition Uganda. Accessed on 29 March 2019 https://info@accu.or.ug

Katureebe, O.K. (2019). State House Anti-corruption Unit requires your support. The Daily Monitor, Wednesday February 20. Accessed: https://www.monitor.co.ug/691150691150/icavj.index.html 13/04/19 
Krylova, Y. (2018). Administrative corruption and its effects on Russian entrepreneurs: a regional aspect. Journal of Small Business \& Entrepreneurship, 30(2), 121-37.

Lasslett, K. (2017). Uncovering the transnational networks, organisational techniques and state corporate ties behind grand corruption: Building an investigative methodology. International Journal for Crime, Justice and Social Democracy, 6(4), 29-54.

Mbau, R., and Gilson, L. (2018). Influence of organisational culture on the implementation of health sector reforms in low- and middle-income countries: a qualitative interpretive review. Global Health Action, 11(1). Accessed: DOI:10.1080/16549716.2018.1462579.

Mitchell, S.L., Oakley, D.R., and Dunkle, J.H. (2019). White paper: a multidimensional understanding of effective university and college counselling centre organisational structures. Journal of College Student Psychotherapy, 33(2), 89-106.

Molina, E. Carella, L. Pacheco, A. Cruces, G. \& Gasparini, L. (2017). Community monitoring interventions to curb corruption and increase access and quality in service delivery: a systematic review. Journal of Development Effectiveness, 9(4), 462-99.

Mondlane, H.T.C., Claudio, F., and Khan, M.A. (2016). Remedying Africa's self-propelled corruption: the missing link. Politikon, 43(3), 345-370.

Moulick A.G. \& Taylor, L.L. (2017). Fiscal slack, budget shocks, and performance in public organisations: evidence from public schools. Public Management Review, 19(7), 990-1005.

Moussa, M. McMurray, A. \& Muenjohn, N. (2018). Innovation in public sector organisations. Cogent Business \& Management, 5(1).

Mugisha, S., and Borisova, T. (2010). Balancing coverage and financial sustainability in pro-poor water service initiatives: a case of a Uganda project. The Engineering Economist, 55(4), 305327.

Muhumuza, W. (2016). The politics of anti-corruption reforms and reversals in Uganda's changing political terrain. Economic and Political Studies, 4(1), 62-84.

Muldoon, K.A., Akello, M., Muzaaya, G., Simo, A., Shoveller, J., and Shannon, K. (2017). Policing the epidemic: High burden of workplace violence among female sex workers in conflictaffected northern Uganda. Global Health, 12(1), 84-97.

Mutonyi, J. (2002). Fighting corruption: is Kenya on the right track? Police practice and research, $3(1), 21-39$.

Mwelu, N., Davis, P.R., Ke, Y., Watundu, S., and Jefferies, M. (2019). Success factors for implementing Uganda's public road construction projects. International Journal of Construction Management. Accessed: DOI: 10.1080/15623599.2019.1573481.

Nystrand, M.J. (2014). Petty and grand corruption and the conflict dynamics in Northern Uganda. Third World Quarterly, 35(5), 821-835.

Pillay, S. (2014). An institutional theory perspective on corruption. In: Development corruption in South Africa. NY: Palgrave Macmillan.

Pitan, O.S. (2016). Towards enhancing University graduate employability in Nigeria. Journal of Sociology and Social Anthropology, 7(1), 1-11.

Quarcoo, S.C. (2009). Prosecution politics: Recalibrating the role of prosecution within the anticorruption agency agenda. African Security Review, 18(4), 32-49.

Rose, J. (2018). The meaning of corruption: testing the coherence and adequacy of corruption definitions. Public Integrity, 20(3), 220-233.

Sabiiti, J. (2019). Chris Obore sacking exposes the intrigue, deals in Parliament recruitment process. The Nile Post, April 12. Accessed https://nilepost.co.ug/category/new/ 13/04/19

Scanlan, G. (2004). The control of corruption. Journal of Financial Crime, 11(4), 316-321.

Sindik, A. (2015). Attempting to reduce uncertainty: lobbying in a competitive communications environment. Journal of Media Business Studies, 12(2), 121-37.

Tangri, R. \& Mwenda, A.M. (2008). Elite corruption and politics in Uganda. Commonwealth \& Comparative Politics, 46(2), 177-194. 
Tumwebaze, Z., Mukyala, V., Ssekiziyivu, B., Tirisa, B.C., and Tumwebonire, A. (2018). Corporate governance, internal audit function and accountability in statutory corporations. Cogent Business \& Management, 5(1).

Tvedten, I. \& Picardo, R. (2019). 'Goats eat where they are tied up': illicit and habitual corruption in Mozambique. Review of African Political Economy, Accessed: 10.1080/03056244.2018.1546686

Umam, A.K. Whitehouse, G. Head, B. \& Khan, M.A. (2018). Addressing corruption in post-Soeharto Indonesia: The role of the corruption eradication commission. Journal of Contemporary Asia. Accessed: 10.1080/00472336.2018.1552983.

Whelan, C. (2015). Managing dynamic public sector networks: effectiveness, performance, and a methodology framework in the field of national security. International Public Management Journal, 18(4), 536-567.

Willis, G.D. (2018). Violence, Bureaucracy and intreccio in Brazil. Global Crime, 19(3-4), 296-314.

Yekini, K.C., Adelopo, I., and Adegbite, E. (2017). The impact of community expectations of corporate community involvement disclosures in the UK. Accounting Forum, 41(3), 234-252. 